\title{
Copper iodide nanoparticles on poly(4-vinylpyridine): A new and efficient catalyst for the synthesis of 1,8-dioxooctahydroxanthenes under solvent-free conditions
}

\author{
JALAL ALBADI $^{\mathrm{a}, *}$, MOSADEGH KESHAVARZ $^{\mathrm{b}}$, MASOUMEH ABEDINI $^{\mathrm{c}}$ and \\ MOLOUD KHOSHAKHLAGH ${ }^{\mathrm{b}}$ \\ ${ }^{a}$ Khatam Al-Anbia, University of Technology, Behbahan 6361647189, Iran \\ b Department of Chemistry, Yasouj University, Yasouj 6361647189, Iran \\ ${ }^{\mathrm{c}}$ Department of Chemistry, Gachsaran Branch, Islamic Azad University, Gachsaran 6361647189, Iran \\ e-mail: Chemalbadi@gmail.com
}

MS received 18 March 2012; revised 9 June 2012; accepted 10 July 2012

\begin{abstract}
Poly(4-vinylpyridine)-supported nanoparticles of copper(I) iodide is reported as a new, efficient and recyclable catalyst for the synthesis of 1,8-dioxooctahydroxanthenes under solvent-free conditions. This catalyst can be recovered by simple filtration and recycled up to 10 consecutive runs without losing of its efficiency.
\end{abstract}

Keywords. Poly(4-vinylpyridine) supported; nano particles; copper(I) iodide; 1,8-dioxooctahydroxanthenes; 1,3-dicarbonyl compounds.

\section{Introduction}

Xanthenes and benzoxanthenes are important class of compounds that received significant attention from many pharmaceutical and organic chemists essentially because of the broad spectrum of their biological and pharmaceutical properties such as antibacterial, ${ }^{1}$ antiinflammatory, ${ }^{2}$ and antiviral ${ }^{3}$ properties. Furthermore, these compounds are used as dyes, ${ }^{4}$ fluorescent material for visualization of biomolecules ${ }^{5}$ and in laser technologies due to their useful spectroscopic properties. ${ }^{6}$ In particular, xanthenediones constitute a structural unit in a number of natural products and have been used as versatile synthase because of the inherent reactivity of the inbuilt pyran ring. ${ }^{7}$ Therefore, various synthetic procedures have been developed for the preparation of xanthenediones. ${ }^{8-16}$ However, some of these methods involve the use of expensive reagents, toxic solvents, tedious work-up, low yields, long reaction times and harsh reaction conditions. Under this light, there is a scope to develop an alternative method for the synthesis of xanthenes derivatives. Polymersupported reagents have more and more attracted attention as insoluble material in organic synthesis. ${ }^{17}$ They

*For correspondence recommend rewards such as reaction monitoring as well as improved safety, more than ever before when the non-supported reagents are toxic or unsafe as they can be easily removed from reaction medium and recycled. ${ }^{18}$ Additionally, employing an excess amount of reagent is permitted without the need for further purification. In recent years, nano-catalysis has emerged as a sustainable and competitive alternative to conventional catalysis since the nanoparticles possess a high surfaceto-volume ratio, which enhances their activity and selectivity, while at the same time maintaining the intrinsic features of a heterogeneous catalyst. ${ }^{19}$ In particular, the immobilization of copper(I) salts nanoparticles (CuNPs) on high-surface-area allows a higher stability and dispersity of the particles as well as further exploitation of the special activity and recycling properties of the catalyst.

\section{Experimental}

\subsection{General}

All products were identified by comparison of their spectral, TLC and physical data with authentic samples. Chemicals were purchased from Fluka, Merck and Aldrich Chemical companies. Yields refer to isolated pure products. 


\subsection{General procedure for preparation of the polymer supported catalyst}

$\mathrm{CuI}(0.381 \mathrm{mg})$ was dissolved in $30 \mathrm{~mL}$ ethanol, and magnetically stirred at reflux temperature for $4 \mathrm{~h}$ under a nitrogen atmosphere in the presence of of dry poly(4-vinylpyridine) (1.0 g, mesh 50-60). The solvent was drawn off and the resin washed with $\mathrm{CH}_{3} \mathrm{CN}$ $(2 \times 20 \mathrm{~mL})$ and dried under vacuum at $60^{\circ} \mathrm{C}$ overnight. The weight increase was $0.31 \mathrm{~g}(1.63 \mathrm{mmol} \mathrm{CuI})$, which

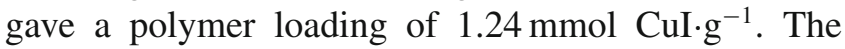
exact copper content of poly(4-vinylpyridine)-CuI was measured using ICP-AES. The loading of supported

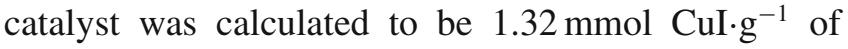
resin.

\subsection{Determination of the copper content in $\mathrm{P}_{4} \mathrm{VPy}-\mathrm{CuI}$}

The $\mathrm{P}_{4}$ VPy-CuI (100 mg) was extracted with concentrated $\mathrm{HCl}(5 \times 2 \mathrm{~mL})$ in a screw-capped vessel, followed by treatment with concentrated nitric acid $(2 \mathrm{~mL})$ to digest the metal complex. The mixture was then transferred into a volumetric flask $(100 \mathrm{~mL})$, diluted 1:50 for the second time and was analysed by the ICP analysis. The copper concentration was determined from the atomic emissions $(324.754 \mathrm{~nm})$ by reference to a linear $(R=0.99)$ calibration curve of $(1-4 \mathrm{ppm})$ of
$\mathrm{CuI}$ prepared in a manner identical to the sample preparation. The loading of supported catalyst was calculated to be $1.32 \mathrm{mmol} \mathrm{CuI} \cdot \mathrm{g}^{-1}$ of prepared catalyst. The same procedure was used to measure the leaching accounts of supported catalyst after 8 consecutive runs.

\subsection{General procedure}

A mixture of dimidone or cyclohexandione (2 mmol), aldehyde (1 mmol) and poly(4-vinylpyridine)-CuI $(0.1 \mathrm{~g})$, was heated in an oil bath $\left(80^{\circ} \mathrm{C}\right)$ for the appropriate time as shown in table 1 . After completion, (monitored by TLC), the mixture was allowed to cool, ethyacetate $(10 \mathrm{~mL})$ was added and the catalyst was recovered to use subsequently by filtration. Evaporation of the solvent from the filtrate and recrystallization of the solid residue from hot ethanol affords the pure products in high yields. The spectral and analytical data for new compounds are as follow:

2.4a Selected spectral data: Table 1, entry 18: White solid, mp: $270-273^{\circ} \mathrm{C}$; IR $(\mathrm{KBr}) v_{\max } / \mathrm{cm}^{-1}: 3070$, 2950, 2900, 2220, 1652, 1619, 1356, 1200, 1173, 1125, 958, 830, 610, 550; ${ }^{1} \mathrm{H}$ NMR (400 MHz, $\mathrm{CDCl}_{3}$ ): d (ppm) 1.95-2.11 (m, 4H), 2.30-2.42 (m, 4H), 2.57$2.73(\mathrm{~m}, 4 \mathrm{H}), 4.84(\mathrm{~s}, 1 \mathrm{H}), 7.44(\mathrm{~d}, \mathrm{~J} 8.0 \mathrm{~Hz}, 2 \mathrm{H})$, 7.53 (d, J $8.0 \mathrm{~Hz}, 2 \mathrm{H}) ;{ }^{13} \mathrm{C} \mathrm{NMR}\left(100 \mathrm{MHz}, \mathrm{CDCl}_{3}\right)$ :

Table 1. Synthesis of 1,8-dioxooctahydroxanthenes catalysed by $\mathrm{P}_{4} \mathrm{VPy}-\mathrm{CuI}$.

\begin{tabular}{|c|c|c|c|c|c|c|}
\hline \multirow[b]{2}{*}{ Entry } & \multirow[b]{2}{*}{ Aldehyde } & \multirow[b]{2}{*}{$\mathrm{R}$} & \multirow[b]{2}{*}{ Time (min) } & \multirow[b]{2}{*}{ Yield $(\%)^{\mathrm{a}}$} & \multicolumn{2}{|c|}{ M. P. $\left({ }^{\circ} \mathrm{C}\right)$} \\
\hline & & & & & Found & Reported \\
\hline 1 & $\mathrm{PhCHO}$ & $\mathrm{CH}_{3}$ & 13 & 88 & $203-204$ & $202-204^{16}$ \\
\hline 2 & $2-\mathrm{NO}_{2} \mathrm{C}_{6} \mathrm{H}_{4} \mathrm{CHO}$ & $\mathrm{CH}_{3}$ & 15 & 89 & $261-262$ & $260-262^{16}$ \\
\hline 3 & $3-\mathrm{NO}_{2} \mathrm{C}_{6} \mathrm{H}_{4} \mathrm{CHO}$ & $\mathrm{CH}_{3}$ & 10 & 89 & $165-167$ & $165-166^{16}$ \\
\hline 4 & $4-\mathrm{NO}_{2} \mathrm{C}_{6} \mathrm{H}_{4} \mathrm{CHO}$ & $\mathrm{CH}_{3}$ & 7 & 90 & $222-224$ & $223-225^{16}$ \\
\hline 5 & $2-\mathrm{ClC}_{6} \mathrm{H}_{4} \mathrm{CHO}$ & $\mathrm{CH}_{3}$ & 10 & 90 & $225-227$ & $226-227^{16}$ \\
\hline 6 & $4-\mathrm{ClC}_{6} \mathrm{H}_{4} \mathrm{CHO}$ & $\mathrm{CH}_{3}$ & 8 & 90 & $225-226$ & $226-228^{16}$ \\
\hline 7 & $4-\mathrm{FC}_{6} \mathrm{H}_{4} \mathrm{CHO}$ & $\mathrm{CH}_{3}$ & 10 & 88 & $227-228$ & $226-227^{16}$ \\
\hline 8 & $4-\mathrm{MeC}_{6} \mathrm{H}_{4} \mathrm{CHO}$ & $\mathrm{CH}_{3}$ & 12 & 87 & $217-218$ & $215-216^{16}$ \\
\hline 9 & $2-\mathrm{MeOC}_{6} \mathrm{H}_{4} \mathrm{CHO}$ & $\mathrm{CH}_{3}$ & 25 & 87 & $189-191$ & $188-190^{16}$ \\
\hline 10 & $4-\mathrm{MeOC}_{6} \mathrm{H}_{4} \mathrm{CHO}$ & $\mathrm{CH}_{3}$ & 28 & 85 & $241-243$ & $242-243^{16}$ \\
\hline 11 & $3,4-(\mathrm{MeO})_{2} \mathrm{C}_{6} \mathrm{H}_{3} \mathrm{CHO}$ & $\mathrm{CH}_{3}$ & 36 & 86 & $176-178$ & $175-176^{16}$ \\
\hline 12 & $4-\mathrm{CNC}_{6} \mathrm{H}_{4} \mathrm{CHO}$ & $\mathrm{CH}_{3}$ & 14 & 85 & $215-217$ & $217-218^{16}$ \\
\hline 13 & $4-\mathrm{OHC}_{6} \mathrm{H}_{4} \mathrm{CHO}$ & $\mathrm{CH}_{3}$ & 35 & 86 & $248-250$ & $247-248^{16}$ \\
\hline 14 & $\mathrm{PhCHO}$ & $\mathrm{H}$ & 12 & 90 & $266-268$ & $267-269^{21}$ \\
\hline 15 & $4-\mathrm{BrC}_{6} \mathrm{H}_{4} \mathrm{CHO}$ & $\mathrm{H}$ & 9 & 90 & $283-285$ & $284-286^{21}$ \\
\hline 16 & $4-\mathrm{ClC}_{6} \mathrm{H}_{4} \mathrm{CHO}$ & $\mathrm{H}$ & 8 & 91 & $284-286$ & $286-288^{21}$ \\
\hline 17 & $4-\mathrm{MeOC}_{6} \mathrm{H}_{4} \mathrm{CHO}$ & $\mathrm{H}$ & 30 & 86 & $202-203$ & $200-201^{21}$ \\
\hline 18 & $4-\mathrm{CNC}_{6} \mathrm{H}_{4} \mathrm{CHO}$ & $\mathrm{H}$ & 12 & 90 & $273-275$ & - \\
\hline 19 & $3-\mathrm{BrC}_{6} \mathrm{H}_{4} \mathrm{CHO}$ & $\mathrm{H}$ & 8 & 87 & $281-283$ & - \\
\hline 20 & $3-\mathrm{MeOC}_{6} \mathrm{H}_{4} \mathrm{CHO}$ & $\mathrm{H}$ & 30 & 88 & $192-194$ & - \\
\hline
\end{tabular}

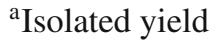


d (ppm) 20.2, 27.1, 32.3, 36.8, 110.2, 115.8, 119.10, 129.4, 132.0, 149.7, 164.5, 196.5 .

Table 1, entry 19: White solid, mp: $281-283^{\circ} \mathrm{C}$; IR (KBr) $v_{\max } / \mathrm{cm}^{-1}: 3070,2910,2890,1660,1620,1560$, $1470,1420,1358,1200,1170,1122,957,800,680 ;{ }^{1} \mathrm{H}$ NMR (400 MHz, $\left.\mathrm{CDCl}_{3}\right)$ : d (ppm) 1.95-2.1 (m, 4H), 2.30-2.44 (m, 4H), 2.55-2.63 (m, 2H), 2.66-2.73 (m, 2H), 4.79 (s, 1H), 7.11 (t, J 7.6 Hz, 1H), 7.26-7.36 (m, $3 \mathrm{H}) ;{ }^{13} \mathrm{C}$ NMR (100 MHz, $\mathrm{CDCl}_{3}$ ): d (ppm) 20.3, 27.2, $31.6,36.9,116.3,122.3,127.7,129.6,131.0,146.6$, 164.3, 196.4 .

Table 1, entry 20: White solid, mp: $192-194^{\circ} \mathrm{C}$; IR (KBr) $v_{\max } / \mathrm{cm}^{-1}: 3070,2950,1650,1605,1580,1450$, $1360,1265,1220,1200,1180,1130,1050,960 ;{ }^{1} \mathrm{H}$ NMR (400 MHz, $\left.\mathrm{CDCl}_{3}\right)$ : d (ppm) 1.99-2.1 (m, 4H), 2.3-2.45 (m, 4H), 2.54-2.71 (m, 4H), $3.81(\mathrm{~s}, 3 \mathrm{H})$, $4.83(\mathrm{~s}, 1 \mathrm{H}), 6.69-6.71\left(\mathrm{dd}, \mathrm{J}_{1} 8.0 \mathrm{~Hz}, \mathrm{~J}_{2} 1.6 \mathrm{~Hz}, 1 \mathrm{H}\right)$, 6.89-6.95 (m, 2H), $7.17(\mathrm{t}, \mathrm{J} 8.0 \mathrm{~Hz}, 1 \mathrm{H}) ;{ }^{13} \mathrm{C} \mathrm{NMR}$ $\left(100 \mathrm{MHz}, \mathrm{CDCl}_{3}\right): \mathrm{d}$ (ppm) 20.3, 27.2, 31.5, 37.0, $55.2,111.5,114.5,116.8,121.0,129.0,146.0,159.4$, 164.0, 196.5.

\section{Results and discussion}

We report here the applicability of a new, green and reusable catalytic system based on $\mathrm{Cu}(\mathrm{I})$ nanoparticles supported by poly(4-vinylpyridine) $\left(\mathrm{P}_{4} \mathrm{VPy}-\mathrm{CuI}\right)$ for one-pot multicomponent synthesis of 1,8-dioxooctahydroxanthenes from cyclic 1,3-dicarbonylcompounds (dimedone and 1,3cyclohexadione) with aldehydes in the absence of solvent (scheme 1).

The copper(I) iodide catalyst immobilized on poly(4vinylpyridine) was readily prepared in a one-step procedure. Poly(4-vinylpyridine) was refluxed with a solution of $\mathrm{CuI}$ under $\mathrm{N}_{2}$ atmosphere in EtOH to afford the polymer-supported $\mathrm{CuI}$ nanoparticles. This method was developed for the effective synthesis of copper nanoparticles incorporated heterogeneously as catalyst in some organic reactions. ${ }^{20}$

Scanning electron microscopy (SEM), X-ray diffraction (XRD) analysis, atomic absorption and IR experimental techniques were used to characterize the catalyst. The SEM image of the prepared catalyst indicated
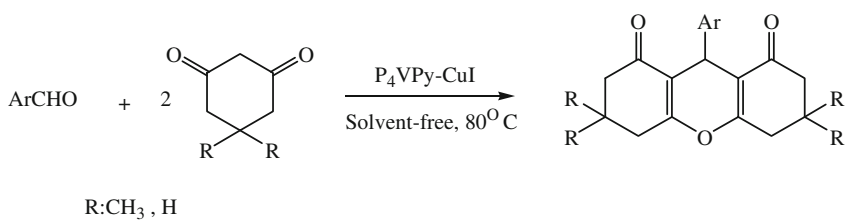

Scheme 1. Synthesis of 1,8-dioxo-octahydroxanthene derivatives under solvent-free conditions. that $\mathrm{CuI}$ nanoparticles were homogeneously immobilized on poly(4-vinylpyridine) surface (figure 1).

According to the SEM images of $\mathrm{P}_{4} \mathrm{VPy}-\mathrm{CuI}$, the average size of copper nanoparticles was estimated to be $75-100 \mathrm{~nm}$. The sharp peaks were observed in the XRD patterns of $\mathrm{P}_{4} \mathrm{VPy}-\mathrm{CuI}$ and their positions were consistent with metallic copper and copper iodide nanocrystals. The size of copper nanoparticles was also determined from X-ray line broading using the DebyeScherrer formula (obtained size: $75 \mathrm{~nm}$ ). At first, for the optimization of the reaction conditions, the reaction between benzaldehyde and dimidone was investigated as a model and its behaviour was studied under a variety of conditions. The best result was achieved by carrying out the reaction of benzaldehyde and dimidone (with 1:2 mol ratio) in the presence of $0.1 \mathrm{~g}$ of $\mathrm{P}_{4} \mathrm{VPy}-\mathrm{CuI}$ in the absence of solvent (table 1, entry 1 ). Using these optimized conditions, the reaction of various aromatic aldehydes, containing electron-donating and electron-withdrawing groups, was explored. All the products were cleanly isolated with simple filtration and evaporation of solvent. The solid products were easily recrystallized from hot ethanol and were obtained in good to high yields during relatively short reaction times.

It is also noteworthy that resin does not suffer from extensive mechanical degradation after running. For a true heterogeneous catalyst, supported catalyst should not leach to the reaction mixture. Moreover, the recyclability of the supported catalyst is also important. To investigate these properties for our introduced catalyst, the reaction of benzaldehyde with dimidone was selected again as model (table 2). After completion of the reaction, the recovered catalyst was washed with acetone and after dryness was reused in the next similar

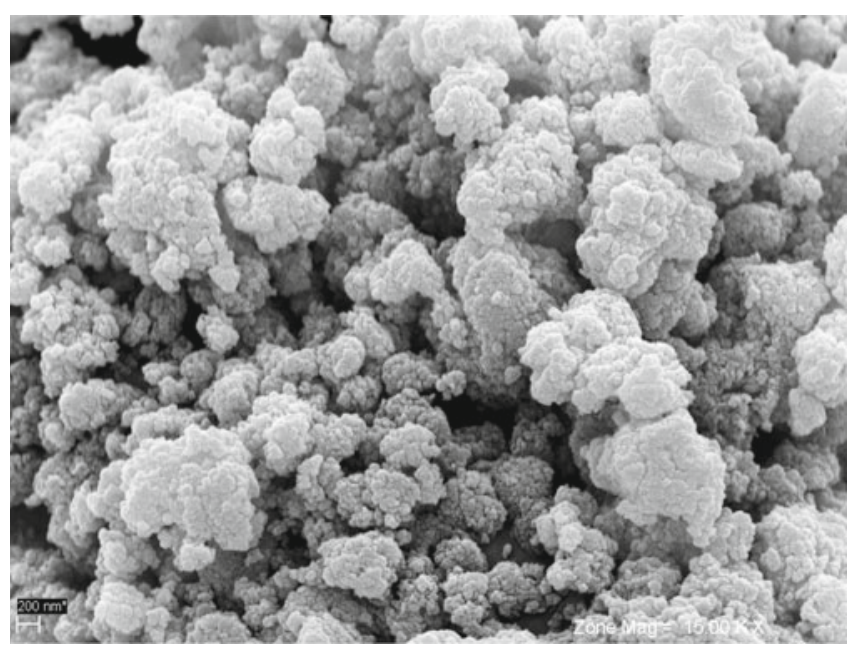

Figure 1. SEM image of poly(4-vinylpyridine)-supported $\mathrm{CuI}$ nanoparticles. 
Table 2. Recyclability study of $\mathrm{P}_{4} \mathrm{VPy}-\mathrm{CuI}$.

\begin{tabular}{lcccccccc}
\hline Run & 1 & 2 & 3 & 4 & 5 & 6 & 7 & 8 \\
\hline Tim (min) & 12 & 12 & 15 & 16 & 18 & 20 & 20 & 25 \\
Yield $(\%)^{\text {a }}$ & 89 & 89 & 87 & 86 & 84 & 84 & 81 & 79 \\
\hline
\end{tabular}

${ }^{\mathrm{a}}$ Isolated yield

run. This procedure was repeated for 8 consecutive runs and the results of this study are represented in table 2 .

The results showed that the polymer supported $\mathrm{CuI}$ can be re-used up to 8 runs without any significant decrease in the yields. Almost consistent activity was observed over 8 runs. However, it can be seen that as the recycling steps were increased, slight decrease in the rate of the reactions was observed. Next, we checked the leaching of $\mathrm{CuI}$ into the reaction mixture from the poly(4-vinyl pyridine) support using ICP-AES. The difference between the copper content of the fresh and reused catalyst (8th run) was only $3 \%$ which indicated the low leaching amount of copper iodide catalyst into the reaction mixture.

\section{Conclusion}

We have developed a mild, simple and green procedure for the one-pot synthesis of 1,8dioxooctahydroxanthenes using recyclable $\mathrm{P}_{4} \mathrm{VPy}-\mathrm{CuI}$ under solvent-free conditions. The introduced catalyst can promote the yields and reaction times. This catalyst showed excellent activity during 8 consecutive runs with very low leaching amounts of supported catalyst into the reaction mixture. Moreover, ease of work-up and clean procedure, will make the present method an useful and important addition to the present methodologies for the synthesis of 1,8-dioxooctahydroxanthenes.

\section{Acknowledgements}

The authors are thankful to the Khatam Al-Anbia, University of Technology, for partial financial support to carry out this work.

\section{References}

1. Hideo T, Jpn. Tokkyo Koho JP567005480 1981 Chem. Abstr. 95 80922b

2. Poupelin J P, Saint-Ruf G, Foussard-Blanpin O, Narcisse G, Uchida-Ernouf G and Lacroix R 1978 Eur. J. Med. Chem. 1367

3. Lambert R W, Martin J A, Merrett J H, Parkes K E B and Thomas G 1997 J. Chem. Abstr. 12621377

4. Banerjee A and Mukherjee A K 1981 Stain Technol. 5683

5. Knight C G and Stephens T 1989 Biochem. J. 258683

6. Sirkecioglu O, Tulinli N and Akar A 1995 J. Chem. Res. (S). 502

7. Dabiri M, Baghbanzadeh M and Arzroomchilar E 2008 Catal. Commun. 9939

8. Nowrouzi N and Jonaghani M Z 2011 Tetrahedron Lett. 525801

9. Manjo P and Shriniwas S 2010 Synth. Commun. 403734

10. Das B, Thirupathi P, Mahender I, Reddy K R, Ravikanth B and Nagarapu L 2007 Catal. Commun. 8535

11. Kemdeo S M, Sapkal V S and Chaudhari G N 2010 J. Mol. Catal A: Chem. 32370

12. Das B, Thirupathi P, Mahender I, Reddy, V S and Rao Y K 2006 J. Mol. Catal. A. Chem. 247233

13. Koley D, Colon O C and Savinov S N 2009 Org. Lett. 114172

14. Seyyedhamzeh M, Mirzaei P and Bazgir A 2008 Dyes. Pigm. 76836

15. Zhang-Hui Z, Peng Z, Shu-Hong Y, Hong-Juan W and Jia D 2010 J. Chem. Sci. 122427

16. Lu H Y, Li J J and Zhang Z H 2009 Appl. Organometal. Chem. 23165

17. (a) Kirschning A, Monenschein $\mathrm{H}$ and Wittenberg $\mathrm{R}$ 2001 Angew. Chem. Int. Ed. 40 650; (b) Hodge P 2005 Ind. Eng. Chem. Res. 448542

18. (a) Galaffu N, Sechi G and Bradly M 2005 Mol. Divers. 9 63; (b) Erb B, Kucma J P, Mourey S and Struber F 2003 Chem. Eur. J. 92582

19. Astruc D 2008 Nanoparticles and catalysis Weinheim: Wiley-VCH

20. Sharghi H, Khalifeh M and Doroodmand M $2009 A d v$. Synth. Catal. 351207

21. Fang D, Gong K and Liu Z L 2009 Catal. Lett. 127291 